\title{
A MARKOVIAN APPROACH TO THE MODELING OF SOUND PROPAGATION IN URBAN STREETS
}

\author{
ZAITON HARON $^{1 *} \&$ DAVID OLDHAM ${ }^{2}$
}

\begin{abstract}
This paper examined the capability of the novel approach called Markov in the simulation of sound propagation in streets. The approach assumes that the facades lining the streets absorb and reflect sound diffusely. The simulation process treated the sound propagation process as first order Markov process characterised by a matrix of transition probabilities relating to sound radiation between surfaces. The results of simulation using Markov model were compared with the results obtained from a commercial model, RAYNOISE using the diffuse reflection option. The results showed that sound pressure level in a street predicted by the Markov model was in good agreement with predictions obtained using RAYNOISE model. This suggests that the Markov model has the potential to predict multiple reflections for diffuse boundary conditions. The effects of distribution absorption of building facades were also investigated and within the scope and assumptions in this study, it is shown streets with absorbent building facade result in sound reductions typically less than $1 \mathrm{~dB}$.
\end{abstract}

Keywords: Diffuse reflection; Markov process; transition probability; sound propagation; noise control

\begin{abstract}
Abstrak. Kertas kerja ini menguji kebolehan kaedah novel, iaitu Markov untuk tujuan simulasi pengorakan bunyi di jalan raya. Kaedah ini menganggap deretan bangunan di tepi jalan menyerap dan memantulkan bunyi secara berserak. Proses simulasi menganggap proses pengorakan bunyi sebagai proses Markov jujukan pertama bercirikan matrix kebarangkalian perpindahan pancaran bunyi di antara permukaan-permukaan. Keputusan simulasi menggunakan kaedah Markov dibandingkan dengan keputusan diperolehi dari model kommersial RAYNOISE dengan menggunakan pilihan pantulan berserak. Hasil keputusan menunjukan paras tekanan bunyi di jalan raya yang diramal oleh kaedah Markov mempunyai kesepadanan yang baik dengan ramalan diperolehi dari model RAYNOISE. Ini menunjukan kaedah Markov mempunyai potensi untuk meramal pantulan berganda bagi keadaan sempadan berserak. Kesan agihan serapan permukaan bangunan juga dikaji, dan dengan skop dan anggapan kajian didapati jalan raya yang mempunyai deretan bangunan berpermukaan menyerap bunyi berupaya menghasilkan pengurangan bunyi kurang dari $1 \mathrm{~dB}$.
\end{abstract}

Kata kunci: Pantulan berserak; proses Markov; kebarangkalian perpindahan; pengorakan bunyi; kawalan bunyi bising

1 Construction Technology Management Centre, Faculty of Civil Engineering, Universiti Teknologi Malaysia, Skudai, Johor, Malaysia

2 Acoustic Research Unit, School of Architecture, University of Liverpool, UK

* Corresponding author: Tel: 07-5531537. Fax: 07-5566157. Email: zaitonharon@gmail.com 


\subsection{INTRODUGTION}

The propagation characteristics of city streets is a topic of considerable current interest and a number of models have been developed based upon façade reflections [1]. Models may be either specular [2-5], diffuse [6-13] or mixed [14-16]. Ismail and Oldham [1] have demonstrated that, for the case of mixed specular and diffuse reflections, the specular component will diminish rapidly with increased orders of reflection leading to the dominance of diffuse sound fields and thus the diffuse models will tend to be more accurate. A diffuse reflection is the process of reflection from any surface that has a roughness, naturally or by design, with a size of the order of a wave length in the frequency band [17]. One method that currently assume diffusely reflecting façades in modelling of sound propagation in a city street is Radiosity [6-10]. Through this method, Kang [7] has suggested that diffusely reflecting facades and obstacles may be a possible noise control method for sound in streets.

A number of acoustical modelling software packages using hybrid and mirror image source methods have also modeled the propagation of sound based on diffuse reflection by using the Monte Carlo approach. One such software package is RAYNOISE [18] which incorporates the facility for specifying and calculating the effect of a fraction of sound energy which is reflected diffusively rather than specularly. The software combined the advantage of both the ray tracing and mirror image source method. The position of source images are located by a beam tracing using cone or triangular beams and the direction of diffuse reflection is determined by random number.

In this paper the prediction of sound propagation in streets based upon treating propagation as a Markov process is proposed. The urban streets containing building facades is also assumed reflected sound diffusely. A Markov process considers the states which change with time. The possible transitions between states can be described in terms of a probability or transition matrix where an element denoted by pij denotes the probability of a transition from state $i$ to state $j$. The fundamental requirements for a Markov matrix are: (i) All elements are non-negative and (ii) The sum of each column is 1 . Suggested by Gerlach [19], reverberation could be modeled as a Markov process because the energy falling on a surface of an enclosure will be reflected and distributed to all the surfaces in a room according to their "visibility" with respect to the reflecting surface. This can be interpreted in terms of probability where the fraction of the reflected sound energy reaching a particular surface is equivalent to the probability of reflected energy reaching that surface. Transitions correspond to orders of reflection. The possible transitions between states can be described in terms of a probability or transition matrix. 
The paper begins with the basic modelling process i.e. the transition probability matrix, source distribution, receiver functions and Markov process. The result from the simulation of noise propagation in streets is compared with the results obtained with a commercial hybrid ray tracing and image source model, RAYNOISE [18] using the diffuse reflection option. The applicability of model to predict sound level for street with the effect of facade absorption, street width and height on sound propagation are investigated.

\subsection{BASIG MODELLING PROGESS}

The model assumes that street facades are to scatter sound from their surfaces in all directions. The street has width, length and height of facades of $w, L$ and $H$, respectively. A Cartesian co-ordinate system is employed with its origin at ground level on the centre line of the street and at one end. Facade 1 and Facade 2 are known as surfaces $I_{T}$ and $J_{T}$ respectively. These surfaces are divided into a number of small rectangular "patches", identified by $i_{x}=1,2 \ldots n$, and $i_{z}=1,2 \ldots m$, and $j_{x}=1,2 \ldots n$, and $j_{x}=1,2 \ldots m$, respectively (Figure 1 ).

The road is assumed to be specularly reflecting. The ground can thus be treated as a plane mirror and the sound source and the patches will have images reflected in the ground plane. Surface $I_{T}$ and $J_{T}$ are used to create the image patches due to reflection in the ground. They are also divided into the same number of patches. For simplicity the source is assumed to be located in the ground plane. This avoids the need to consider possible interference effects as in the work of Horoshenkov et al. [20] and $\mathrm{Iu}$ and $\mathrm{Li}$ [21]. This approach can be justified as the multiple diffuse reflections between facades can be expected to mask as interference effects.

The patch size has to correspond to the condition that the distance between any patch on surface $I$ and any patch on surface $J$ is greater than fives time the projected dimension of a patch. This requirement also applies to the distance between the source to a patch and a patch to a receiver. Thus, each patch can be considered to act as a point source which can radiate a fraction of its total sound energy to other patches. The model assumes that at the first transition considering patch $i$ (Figure 2(a)), the initial energy will be distributed to a patch on surface $J$ and to the ground. An image source of patch $i$ can created in the ground and used to calculate the reflection of sound from the ground to patch $j$ (Figure 2(b)). The image patch has the same energy as the real patch and can also radiate to the receiver. At the second transition, the energy reflected from the ground previously calculated and also from patch $j$ will be distributed to all patches on surface $J$ and again to the ground. 


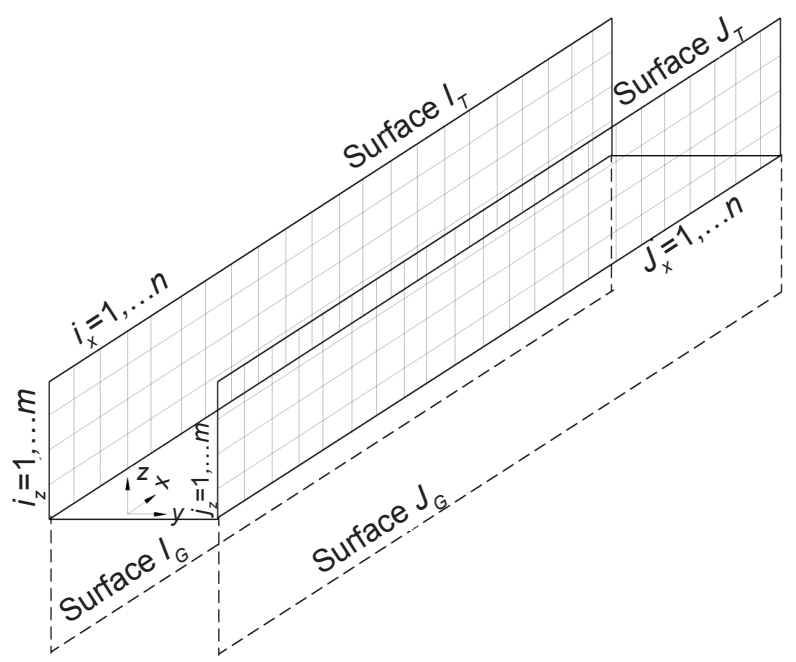

Figure 1 Configuration of street and patch division

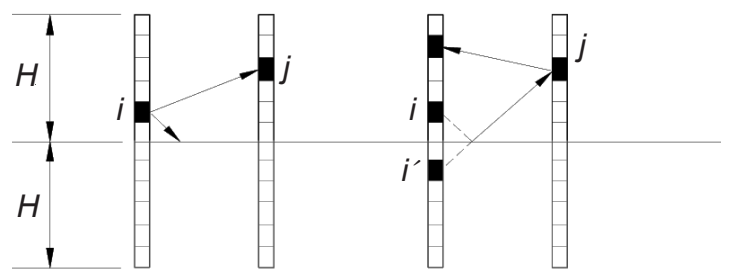

$\begin{array}{ll}\text { (a) First transition } & \text { (b) Second transition }\end{array}$

$$
\begin{aligned}
i & =\text { real patch } \\
i^{\prime} & =\text { image a patch of } i, \text { respectively }
\end{aligned}
$$

Figure 2 Radiation of sound patch to patch with a reflecting ground plane

The transition probability corresponding to the radiation of energy from one patch to another patch is equivalent to projecting the radiating patch onto a unit hemisphere centred about the radiating patch. The solid angle formed by the projected area is then divided by the total solid angle at the base. This is equivalent to the determination of the form factor in the radiosity method [22]. The transition probability matrix will consist of the following:

- Sub matrices for radiation of sound between patches on surfaces $I_{T}$ to $J_{T}$

- Sub matrices for radiation of sound between patches on surfaces $J_{T}$ to $I_{T}$ 
- Sub matrices for radiation of sound between patches on surface $J_{G}$ to surface $I_{T}$ - Sub matrices for radiation of sound between patches on surface $I_{G}$ to surface $J_{T}$

The transition matrix, $P$ can be written as;

$$
P=\left[\begin{array}{cccc} 
& & P_{I_{T} J_{T}} & 0 \\
0 & & & \\
& & P_{I_{G} J_{T}} & 0 \\
P_{I_{T} I_{T}} & 0 & & \\
& & 0 & \\
P_{I_{G} J_{T}} & 0 & &
\end{array}\right]
$$

$P_{I_{T} J_{T}}, P_{I_{T} J_{G}}, P_{I_{G} J_{T}}$ and $P_{I_{G} J_{G}}$ are the sub matrices due to radiation of sound from patches on a surface indicated by the respective subscripts. The transition probability matrix uses the principle of reciprocity where $P_{I_{T} J_{G}}=P_{I_{G} J_{T}}$. The radiation of sound from surfaces $I_{G}$ and $J_{G}$, from surfaces $I_{T}$ to $J_{G}$ and surfaces $J_{T}$ to $I_{G}$ will not occur thus the sub matrices are null. The fraction of sound energy incident on surface $I_{T}$ which radiates to surface $J_{T}$ is determined by multiplying by the reflection coefficient, $\left(1-\alpha_{I}\right)$. The fraction of sound energy incident on surface $J_{T}$ which radiates to surface $I_{T}$ must also be multiplied by $\left(1-\alpha_{J}\right)$. Thus, an effective transition matrix, $P_{e}$ can be obtained as follows;

$$
P_{e}=\left[\begin{array}{rrrr} 
& & P_{I_{T} J_{T}}\left(1-\alpha_{I}\right) & 0 \\
0 & & & \\
& & P_{I_{G} J_{T}}\left(1-\alpha_{I}\right) & 0 \\
P_{J_{T} I_{T}}\left(1-\alpha_{J}\right) & 0 & 0 & \\
P_{J_{G} I_{T}}\left(1-\alpha_{J}\right) & 0 & &
\end{array}\right]
$$

\subsection{Distribution of Sound Energy from Source to Patches and Patches to Receiver}

Before the Markov model can be run it is necessary to distribute the sound energy of a source to the patches which can then be regarded as sound sources, for example to 
a patch on surface $I_{T}$ (Figure 3). The basic principle of the source energy distribution is that the fraction of energy from the source that is incident at each patch is the same as the ratio of the solid angle subtended by the receiving patch divided by the total angle into which energy from the source radiates.

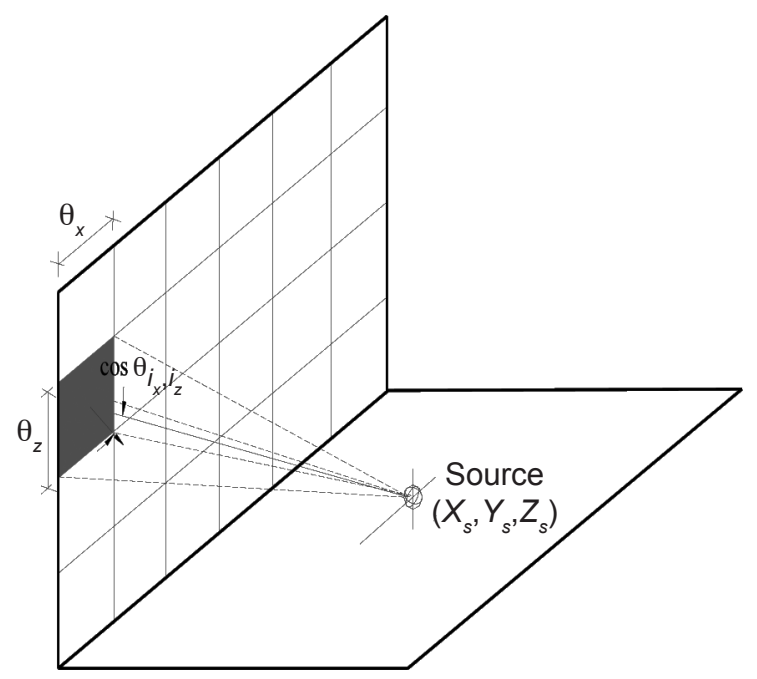

Figure 3 Distribution of sound energy from a source to a patch $i$

The normal intensity at the centre of a patch can be determined using the inverse square law which a point source at ground plane at $\left(x_{s}, y_{s}, z_{s}\right)$ radiate hemispherical. The source properties (sound power spectrum) can be separated out from the geometry to obtain a source function, $S$. for example for patches on surfaces $I_{T}$;

$$
S_{\left(i_{x}, i_{z}\right) T}=\frac{\cos \theta_{\left(i_{i}, i_{z}\right) T}}{2 \pi d_{s,\left(i_{x}, i_{z}\right) T}^{2}}
$$

Where $\left.d_{s,\left(i_{x}, i_{z}\right.}\right)_{T}$ is the distance from the centre of a patch on surface $I_{T}$ to the source and $\cos \theta_{\left(i_{i}, i_{2}\right) T}$ is the angle of incidence of a sound ray from the source to the centre of a patch on surface $J_{T}$.

The source to patch distribution function vector can be written as;

$$
S=\left[\begin{array}{llll}
S_{I_{T}} & S_{J_{T}} & S_{I_{G}} & S_{J_{G}}
\end{array}\right]
$$


Where the sub matrices corresponding to radiation from the source to image patches such as $S_{I_{G}}$ and $S_{J_{G}}$, are null matrices.

The radiation of sound reflected diffusely from a patch and image patch to a receiver can be treated in the same way. The intensity at the receiver due to radiation from a patch can be calculated using the inverse square law to yield a receiver function and distribution vector similar in form to Equations (3) and (4).

\subsection{Energy Response and Markov Process}

The initial energy distribution $E^{0}$ to patches can be written as;

$$
E^{0}=W_{a} \Delta_{x} \Delta_{z}\left[S_{l_{T}}^{(0)} \quad 0 \quad S_{J_{T}}^{(0)} \quad 0\right]
$$

In which $W_{a}$ is the acoustic power of the noise source and $S$ is the source function. $\Delta_{x}$ and $\Delta_{z}$ are the patch dimensions in the $x$ and $z$ directions for surface $I$. It is necessary to use a size of patch which will result in near hemispherical radiation of sound to the other patches. One approach is by specifying the patch dimension $\Delta_{x}$ and $\Delta_{z}$ to ensure that the distance to other patches on surface $J$ and the distance to the receiver is greater than five times the patch dimensions [22].

Note that at this stage, image patches will be assumed exist and initial energy is assigned to surfaces $I_{G}$ and $J_{G}$ equal to that for the real patch. Hence, the initial energy distribution in the model is such that;

$$
E^{0}=W_{a} \Delta_{x} \Delta_{z}\left\lfloor S_{l_{T}}{ }^{(0)} \quad S_{l_{T}}{ }^{(0)} \quad S_{J_{T}}{ }^{(0)}\right\rfloor
$$

The energy distribution after the first transition can be obtained using the transition matrix as follows:

$$
E^{(1)}=\left[E^{(0)}\right] P_{e}
$$

For $q$ orders of transition the total energy at the receiver can be written as:

$$
I_{T}=I_{d}+\sum_{j=1}^{q} I_{r}^{(q)}
$$

Where $I_{r}^{(q)}=E^{(q-1)} A R$.

$R$ is the patch to receiver distribution function vector while $A$ is its absorption array. 
The simulation of sound propagation in a simple street was carried out using MATLAB 7.2 [23]. The computer model calculates the effect of multiple reflections through from facades and the ground. The effect of the ground is taken into account by using image patches. The program consists of seven stages;

(i) The division into patches of surfaces $I$ and $J$,

(ii) The population of the transition probability matrix and effective transition probability matrix,

(iii) Calculation of the source distribution,

(iv) Calculation of the response at a series of receivers,

(v) Determination sound pressure level from the summation of energy at receiver.

The input for the program include the length, width, height of facades, the position of source, the position of receiver, and absorption coefficient of building facades.

\subsection{GOMPARISON BETWEEN RESULTS FROM MARKOV AND RAYNOISE MODELS}

In order to check the validity of the Markov approach, a commercial model, RAYNOISE [18] model was developed in order to compare its predictions with results obtained using the Markov method. The computations were carried out for a street model with length, $L$, and width, $w$, of $100 \mathrm{~m}$ and $10 \mathrm{~m}$, respectively. The height of facades were $10 \mathrm{~m}$ and were assumed to have a uniform absorption coefficient of 0.1 . A point source was located at $(5 \mathrm{~m}, \mathrm{w} / 2,0 \mathrm{~m})$ with a power of 1 watt and the receivers were positioned along line $(10-95 \mathrm{~m}, \mathrm{w} / 2,1.6 \mathrm{~m})$ at intervals of $5 \mathrm{~m}$. The geometry is illustrated in Figure 4.

A length of $100 \mathrm{~m}$ was chosen based on the assumption that in urban areas propagation effects are important for distance up to $200 \mathrm{~m}$ [4]. The width of $10 \mathrm{~m}$ was chosen as a width of less than $10 \mathrm{~m}$ would mean that the street is classified as narrow and propagation might be affected by interference effects due to multiple reflections from buildings and the ground [21]. The model facades were assumed to have a uniform absorption coefficient of 0.1 . This is based on the assumption that the façades consist of large areas of brickwork [24]. Lee and Davies [25], Oldham and Radwan [4] and Kang [6-10] also used an absorption coefficient 0.1 in their models.

To ensure that the source radiates in a hemispherical way, the source emission angle was set at $H_{\text {min }}=-180^{\circ}$ to $H_{\text {max }}=180^{\circ}$ and $V_{\text {min }}$ and $V_{\max }$ equal to $0^{\circ}$ and $90^{\circ}$, 


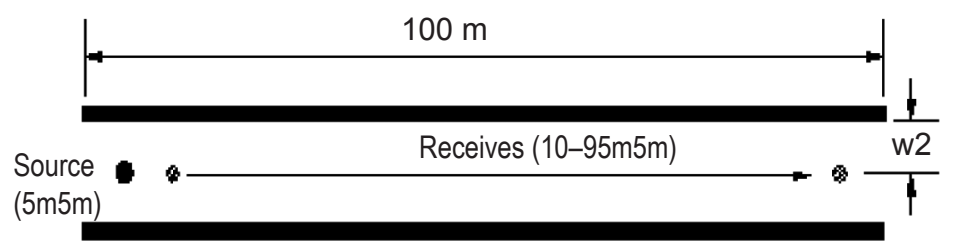

(a) Plan

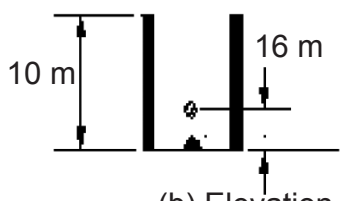

(b) Elevation

Figure 4 Street configuration

respectively. The ground was assumed to be fully reflecting with both the absorption coefficient and the diffusion coefficient set at 0 . The facade absorption coefficient was set to 0.1 and the diffuse coefficient, $d$ was set to 1 to obtain diffuse reflections. The calculation was carried out using 200,000 rays the triangular beam option and 12 reflections. In 3D Markov model calculation, a patch size of $1 \mathrm{~m} \times 1 \mathrm{~m}$ was utilized. The 9 transition orders was used as it was found that it was sufficient to achieve the steady state condition. The sound pressure level in a street containing reflective screens relative to that of the sound pressure level for the street without screens obtained from the 3D Markov and RAYNOISE models is shown in Figure 5. The results from both simulations show a very small effect (approximately a maximum variation of $0.5 \mathrm{~dB}$ ).

\subsection{THE EFFEGT OF ABSORPTION OF BUILDING FAGADES}

The Markov model was used to investigate the effect of different distributions of sound absorption on building facades. Four different cases were examined as follows;

(i) Case I - both facade 1 and facade 2 with absorption coefficients $\alpha_{1}=\alpha_{2}=0.1$

(ii) Case II - both facade 1 and 2 with absorption coefficients $\alpha_{1}=\alpha_{2}=0.2$

(iii) Case III - facade 1 and facade 2 with absorption coefficients, $\alpha_{1}=0.1$ and $\alpha_{2}=$ 0.3 , respectively

(iv) Case IV - both facades with absorption coefficient $\alpha_{1}=\alpha_{2}=0.4$ 


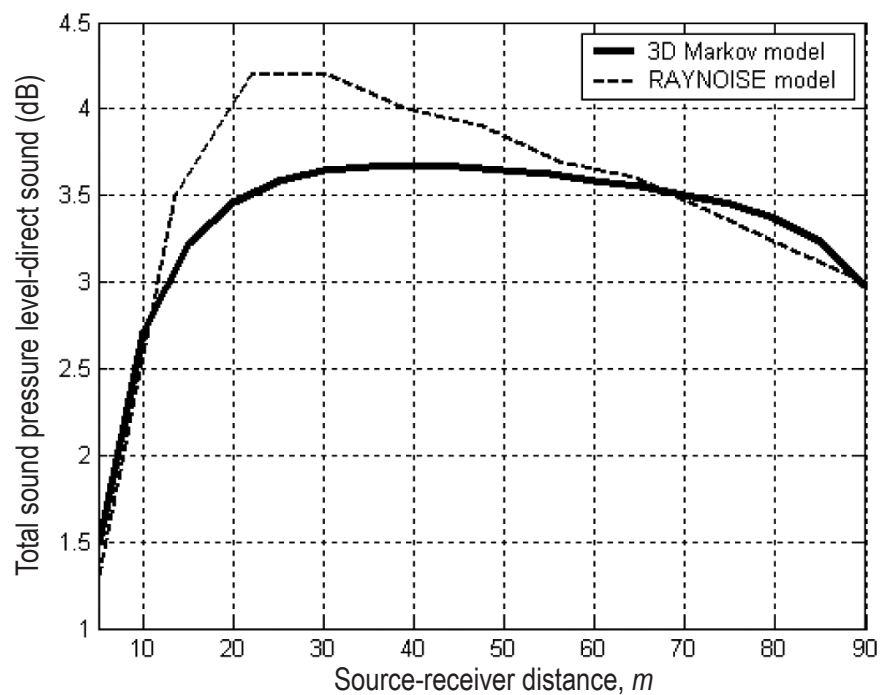

Figure 5 Comparison sound pressure level in a street obtained from the RAYNOISE and the Markov models

The absorption coefficients 0.1 and 0.2 were chosen to be representative of the absorption coefficient of real building facades. Coefficients 0.3 and 0.4 would require the facade to be treated with special absorbing material. Case II was chosen to investigate the effect on the sound field if the absorption coefficient of both facades were doubled. Case III was designed to study the effect if the extra absorption is only concentrated at one facade while maintaining the average absorption coefficient equal to that of Case II. Case IV was chosen to investigate the effect if both facade absorption coefficients are increased to a higher value.

Again the layout of the street as shown in Figure 4 was employed. For the Markov model, a street length and a width of $100 \mathrm{~m}$ and $10 \mathrm{~m}$ were used. A patch size of $1 \mathrm{~m} \times$ $1 \mathrm{~m}$ was employed. RAYNOISE models were run to compare the results. Figures 6 and 7 show the sound propagation characteristics along the street and the relative sound pressure levels for Case I, Case II, Case III and Case IV, respectively. From Figure 6, it can be seen that both the Markov model and the RAYNOISE model give similar results. The replacement of Case I by Case II and III did not result in significant sound pressure level reductions along the street. The sound level reduction obtained from Case IV relative to the sound level obtained from Case I is approximately constant at $1 \mathrm{~dB}$ along the street.

Referring to Figure 7, although the values of relative sound pressure level for both models are similar for all cases, there are some dissimilarities between the trends 


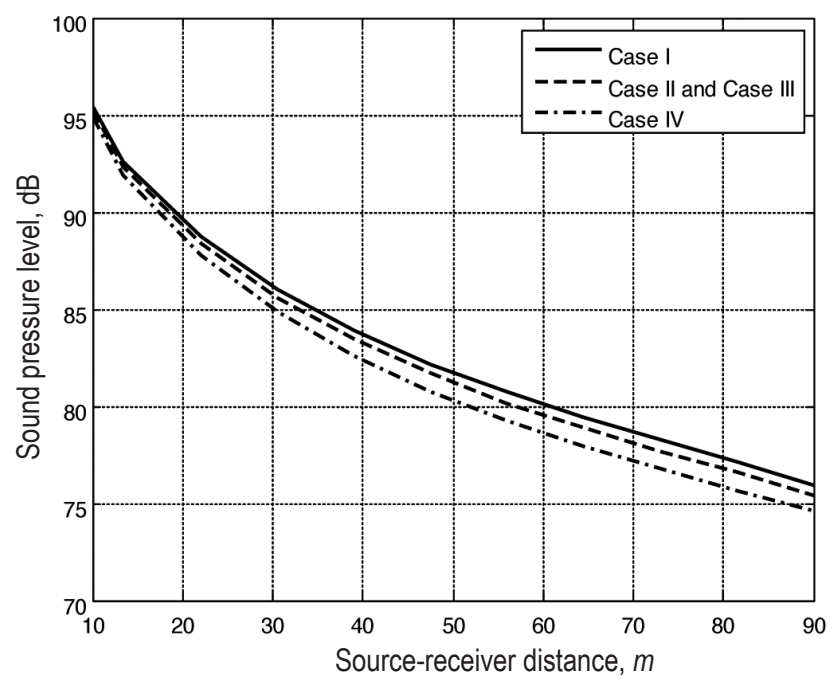

(a) Markov model

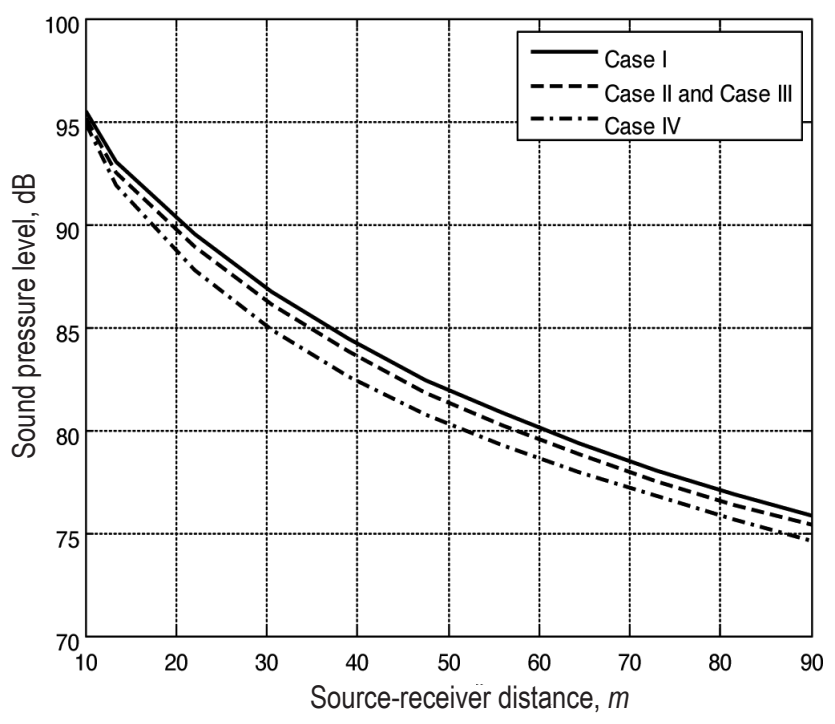

(b) RAYNOISE model

Figure 6 Comparison of variation of level along the street due to various absorption distributions obtained from Markov model and RAYNOISE model

along the source-receiver distance. For example, the relative sound pressure level is approximately constant over the source-receiver distance of 20 to $80 \mathrm{~m}$ for the Markov model while the relative sound pressure level versus distance characteristics obtained 


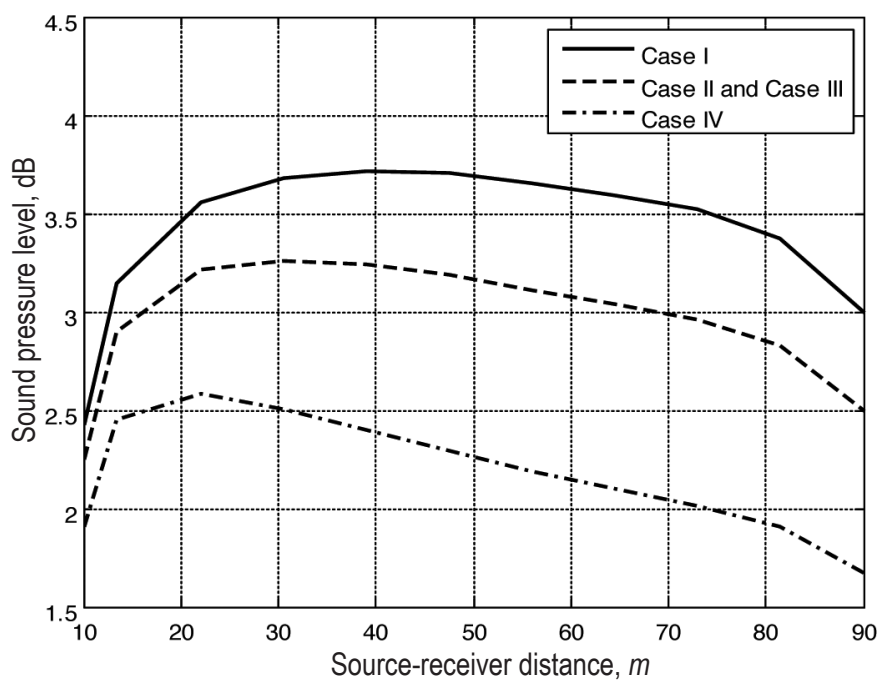

(a) Markov model

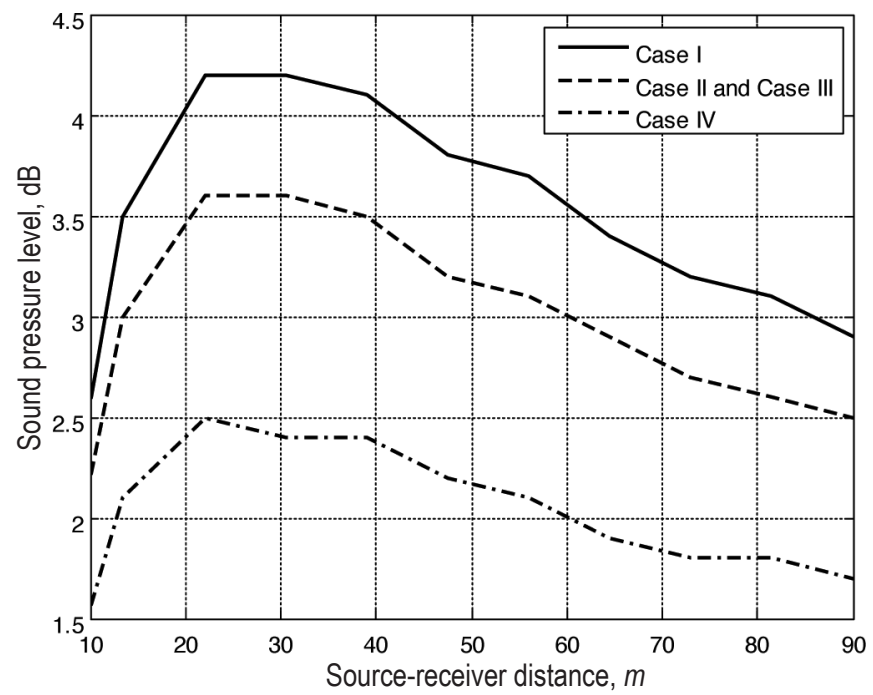

(b) RAYNOISE model

Figure 7 Comparison of variation of level due to various absorption distribution obtained from Markov model and RAYNOISE model

with RAYNOISE has a steeper gradient over this range. However, the differences are insignificant 


\subsection{DISGUSSION}

The key step in the modelling of street propagation using the Markov approach is the discretization of the facades into a number of patches. As in other numerical studies (those using radiosity) use of a finer patch could increase the accuracy of the results $[6,7,9,22,26]$. The discretization should be such as to enable each patch to act as point source. On the other hand, the use of the minimum number of patches is preferable in order to minimize the processing time. In the above street configuration it was found that patch sizes of $5 \mathrm{~m} \times 5 \mathrm{~m}$ and $1 \mathrm{~m} \times 1 \mathrm{~m}$ produced only slight differences in sound level (i.e $0.5 \mathrm{~dB}$ ) but the processing time increased dramatically for the smaller patch sizes. In fact, the patch size of $5 \mathrm{~m} \times 5 \mathrm{~m}$ does not satisfy the requirement of the "five times rule" to act as a point source. However, it provides a very good accuracy of prediction. Therefore, there should be a compromise between the patch size, the accuracy of results obtained and processing time. In view of above, for longer streets (i.e $200 \mathrm{~m}$ ), it is suggested that a coarser patch size such as $5 \mathrm{~m} \times$ $5 \mathrm{~m}$ could be employed. Considering the effect of multiple reflections, it was found that for the Markov approach 9 transition orders are sufficient in order to achieve the steady state condition.

Generally the sound pressure level predictions obtained with the Markov model are in good agreement with RAYNOISE model predictions. This suggests that the Markov model has the potential to predict multiple reflections for diffuse boundary conditions comparable to other numerical methods $[6,7,9,12]$. A good agreement between the results obtained from the above investigation of the effects of width, height, and absorption distribution proved that the effect of diffuse reflections calculated by the Markov process are equivalent with those obtained using a ray tracing hybrid technique with diffuse reflections as employed in RAYNOISE. It was found that some of these results are in agreement with the recent results presented by other researches $[6,7,9]$. It has also been found that the Markov model required shorter processing time compared to the RAYNOISE model with the number of 20,000 rays. The results regarding the effects of different distributions of absorption are of interest in planning for urban noise reduction, eventhough the maximum reduction due to the increase of the absorption coefficient from 0.1 to 0.4 on both facades is only $1 \mathrm{~dB}$.

\subsection{GONGLUSION}

A 3D Markov model for the prediction of sound propagation in streets has been described. It has been shown that the sound pressure level relative predicted by the Markov model is in good agreement with predictions obtained using RAYNOISE 
model and measurements. This shows that Markov approach has the potential to predict the sound field in more complex environments. The technique could also be developed to investigate sound propagation of street containing obstacles and also sound propagation through a region combining a low density of buildings as considered by Leschnick [27] and Kuttruff [28]. Within the scope and assumptions in this study, it is shown the abatement schemes containing absorbent building facades result in sound reductions typically less than $1 \mathrm{~dB}$.

\section{REFERENGES}

[1] Ismail, M. R. and D. J. Oldham. 2003. Computer Modelling of Urban Noise Propagation. Building Acoustics. 10: 221-253.

[2] Radwan, M. M. and D. J. Oldham. 1987. The Prediction of Noise from Urban Traffic Under Interrupted Flow Conditions. Applied Acoustics. 21: 163-185.

[3] Diggory, I. S. and B. Oakes. 1980. Computer Simulation Model for the Prediction of Traffic Noise Levels. Applied. 13: 19-31.

[4] Oldham, D. J. and M. M. Radwan. 1994. Sound Propagation in City Streets. Building Acoustics. 1: 65-88.

[5] Wiener, F. M., G. I. Malme, and C. M. Gogos. 1965. Sound Propagation in Urban Areas. The Journal of the Acoustical Society of America. 37: 738-747.

[6] Kang, J. 2000. Sound Fields in Urban Street with Diffusely Reflecting Boundaries. Proceeding of the Institute of Acoustics. 1: 163-170.

[7] Kang, J. 2000. Sound Propagation in Street Canyon: Comparison Between Diffusely and Geometrically Boundaries. The Journal of the Acoustical Society of America. 107: 1394-1404.

[8] Kang, J. 2002. Computer Simulation of the Sound Fields in Urban Squares: Comparison Between Diffusely and Geometrically Boundaries. The 32nd International Acoustical Conference -EEA Symposium "Acoustics Banka Stiavinca".

[9] Kang, J. 2002. Numerical Modeling of the Sound Fields in Urban Street with Diffusely Reflecting Boundaries. Fournal of Sound and Vibration. 258(5): 793-813.

[10] Kang, J. 2005. Numerical Modeling of the Sound Fields in Urban Squares. The fournal of the Acoustical Society of America. 117(6): 3695-3706.

[11] Picaut, J. and L. Simon, 2001. A Scale Model Experiment for the Study of Sound Propagation in Urban Areas. Applied Acoustics. 62: 327-340

[12] Picaut, J., J. Hardy, and L. Simon. 2002. Numerical Modeling of Urban Sound Fields by A Diffusion Process. Applied Acoustics. 63(9): 965-991.

[13] Heutschi, K. 1995. A Simple Method to Evaluate the Increase of Traffic Noise Emission Level Due to Buildings, for A Long Straight Street. Applied Acoustics. 44: 259-274.

[14] Bullen, R. and F. Fricke. 1977. Sound Propagation in a Street. Journal of Sound and Vibration. 54(1): 33-42.

[15] Davies, H. 1978. Multiple Reflection Diffuse-scattering Model for Noise Propagation in Streets. The Journal of the Acoustical Society of America. 64(2): 517-521.

[16] Wu, S. and E. Kittinger. 1995. On the Relevance of Sound Scattering to the Prediction of Traffic Noise in Urban Streets. Acustica. 81: 36-42. 
[17] Dalenback, B., M. Kleiner, and P. Svensson. 1994. A Macroscopic View of Diffuse Reflection. Journal of Audio Engineering Society. 42(10).

[18] RAYNOISE, User manual, LMS international, Numerical Technologies.

[19] Gerlach, G. 1975. The Reverberation Process as a Markov Chain, Auditorium Acoustics, London: Applied Science.

[20] Horoshenkov, K. V., D. C. Hothersall, and S. E. Mercy. 1999. Scale Modelling of Sound Propagation in A City Street Canyon. Journal of Sound and Vibration. 23(5): 795-819.

[21] Iu, K. K. and K. M. Li. 2002. The Propagation of Sound in Narrow Street Canyons. The Fournal of the Acoustical Society of America. 112(2): 537-550.

[22] Nosal, E. M., M. Hodgson, and I. Ashdown. 2004. Improved Algorithms and Methods for Room SoundField Prediction by Acoustical Radiosity in Arbitrary Polyhedral Rooms. The Fournal of Acoustical Society of America. 116(2): 970-980.

[23] MATLAB. The MathWorks, Inc.

[24] Delany, M. E. 1972. Prediction of Traffic Noise Level. NPL Acoustic Report 56.

[25] Lee, K. P. and H. G. Davies. 1975. Nomogram for Estimating Noise Propagation in Urban Areas. The Fournal of the Acoustical Society of America. 57(6): 1447-1480.

[26] Onaga, H. and J. H. Rindel. 2006. Acoustics Characteristics of Urban Streets in Relation to Scattering Caused by A Building Facades. Applied Acoustics. Article in press.

[27] Leschnick, W. 1980. Zur Schallausbereitung in Bebauten und Bepflanzten Gebieten. Acustica. 44: 115119.

[28] Kuttruff, H. 1982. A Mathematical Model for Noise Propagation Between Buildings. Fournal of Sound and Vibration. 85(1): 115-128. 